\title{
Nurse SRH training and accreditation in Hull, UK
}

We write in response to the article in the July 2012 issue of this Journal by Shelley Mehigan and Janice Burnett entitled 'An innovative training for nurses in sexual health'. ${ }^{1}$ We agree wholeheartedly that a nationally recognised, standardised training for nurses in sexual and reproductive health is needed and that the best way forward may be for the Faculty of Sexual and 
Reproductive Healthcare (FSRH) to accredit nurses or to open up the Faculty Diploma (DFSRH) to nurses. Mehigan and Burnett warn of the dangers of reinventing lots of different wheels. In Hull this is exactly what we have done.

Previous training initiatives to increase the numbers of long-acting reversible contraception (LARC) providers within primary care proved unsuccessful due to low numbers of nurses with the prerequisite qualifications (i.e. a family planning qualification) necessary to access LARC training. In addition, a training needs assessment demonstrated lack of interest in undertaking a lengthy academic pathway to achieve family planning status. To overcome these problems we worked in partnership with commissioners and York St John University to develop a fast-track contraceptive course with 30 credits at degree level to enable nurses to counsel clients about all methods of contraception and to fit and remove subdermal implants.

We do, however, disagree with Mehigan and Burnett about the value of working with a university to ensure that the programme has academic accreditation. Even if the Faculty does eventually accredit nurses and we have a nationally recognised qualification, thus standardising training across the UK, this will not help nurses with their career pathway in the way that transferable academic credit can do. Nursing is now a degree and masters level profession and any training and education needs to reflect the academic level of the knowledge and skills development involved. Nurses within our service in Hull have undergone much training, which has equipped them well in providing safe and effective care for their clients but has left them short on academic qualifications and the credibility that these bring. Working in true collaboration with a local university to achieve academic accreditation has enabled us to maintain ownership of our essentially practical skills-based course, but also given us access to the expertise of educationalists in a higher educational institution to ensure that our assessment processes are rigorous and appropriate. The university, always needing to update its own practices, has benefitted from the opportunity to work with practitioners who are at the forefront of service enhancement. Without accreditation we would not have obtained funding and approval from commissioners to provide this training, which we anticipate will make a real difference to the high unplanned pregnancy rates in our local area and demonstrate a tangible return on investment for all stakeholders.

We are more than willing to work with Mehigan and Burnett or indeed anyone else out there who is trying to reinvent wheels, but to do this effectively we believe that it is important to share practice with academic colleagues and avoid working in silos.

Marian Everett, MBChB, FFSRH

Consultant in Sexual and Reproductive Health, City Health Care Partnership Hull, Conifer House at Wilberforce Health Centre, Hull, UK; Marian.Everett@chcphull.nhs.uk

Carol Totterdell, RN

Professional Development Nurse, Sexual Health, City Health Care Partnership Hull, Longhill Health Care Centre, Hull, UK; Carol.Totterdell@chcphull.nhs.uk

Peter Gray, DipCOT, MMed Ed

Deputy Dean, Faculty of Health and Life Sciences, York St John University, York, UK;

p.gray@yorksj.ac.uk

Competing interests None.

J Fam Plan Reprod Health Care 2013;39:67-68. doi:10.1136/jprhc-2012-100539

\section{REFERENCE}

1 Mehigan S, Burnett J. An innovative training for nurses in sexual health. J Fam Plann Reprod Health Care 2012;38:194-195. 